\title{
An Epidemiological Perspective on Labor Trafficking
}

\section{Michael Gallo, Renata A. Konrad \& Hannah Thinyane}

To cite this article: Michael Gallo, Renata A. Konrad \& Hannah Thinyane (2020): An Epidemiological Perspective on Labor Trafficking, Journal of Human Trafficking, DOI: 10.1080/23322705.2020.1815474

To link to this article: https://doi.org/10.1080/23322705.2020.1815474

\section{Published online: 10 Sep 2020.}

Submit your article to this journal $₫$

Q View related articles ¿

View Crossmark data $\asymp$ 


\title{
An Epidemiological Perspective on Labor Trafficking
}

\author{
Michael Gallo ${ }^{a}$, Renata A. Konrad ${ }^{b}$, and Hannah Thinyane (D) \\ aUnited Nations University Institute in Macau, Macau, SAR China; ${ }^{b}$ Operations and Industrial Engineering, Worcester \\ Polytechnic Institute, Worcester, Massachusetts, USA
}

\begin{abstract}
Ending all forms of labor trafficking by 2030 has been prioritized within the United Nations Sustainable Development Goals (Target 8.7), yet progress in combatting trafficking has been limited. Human trafficking is recognized as a global public health concern because of its widespread negative impacts on individual and population level health. This has led researchers, policymakers, and NGOs to frequently claim that trafficking has reached "epidemic proportions". If such is the case, then using tools from public health and epidemiology can help to generate novel insights in the way we conceptualize, research, and address the problem of trafficking. Using a methodological framework known as the Epidemiologic Problem Oriented Approach (EPOA), we analyze the various components of labor trafficking identification and response, drawing contextualized comparisons with infectious disease epidemiology to characterize labor trafficking as a "disease". This crossdisciplinary approach provides a well-defined conceptual organization of the components that play a role in understanding trafficking dynamics. Epidemiology is highly relevant in the study of trafficking and contributes to the growing research interest surrounding the intersection of public health and human trafficking.
\end{abstract}

\section{KEYWORDS}

Labor trafficking; public health; epidemiology

\begin{abstract}
There are no jobs in Sein's hometown in Myanmar, so he made the hard decision to look for work in Thailand. Sein has been working as a fisherman now for five years. Though the hours are long, and the conditions are harsh, he doesn't mind as he is able to provide for his family. Compared to his previous boss Ohnmar, Cho is a saint, and doesn't take it out on the fishers when the nets don't come up full. Ohnmar was brutal - on one trip the nets kept coming up empty and the crew had to stay out at sea a further 3 days than what they had planned. He didn't let them rest until the hold was full, and because the extended trip was unplanned, they ran out of drinking water. When they returned to port, Ohnmar refused to give extra time off in lieu of the extended time at sea, and only gave Sein a fraction of the salary that he had been promised. Ohnmar had said that this would teach the fishers for not working hard enough. If the fishers complained, Ohnmar would think of another punishment for disrespecting him often keeping them onboard the boat while it was in port. Sein had often considered leaving, but needed the money that Ohnmar owed him. Ohnmar hadn't always been like this - they had grown up in the same village, and Ohnmar had been the one who initially told Sein about his work in Thailand. Three years after Sein joined him on the boat, Ohnmar had been promoted to the position of Chiu - the right-hand man of the captain. It seemed like Ohnmar wanted to prove he was right for the job and deserving of the increased authority (and pay) that the promotion included.
\end{abstract}

Cho was different. He pushed Sein and the crew to work very long hours, but always recorded their days at sea accurately. They often ran trips back to back, stopping only to refuel and resupply the boat. Cho convinced Sein that this was ok, because there was little to do in the village between trips, and he could earn more money to send back to his family. Although Cho had promised them a share of the catch that they hadn't received yet, Sein trusted that it would come. Cho had confided in Sein that he needed the money to pay off some debts. Next week is Thingyan (the Burmese New Year Festival), so the whole crew is looking forward to a week of rest with family. In some of the few quiet hours on the boat, Cho tells Sein to keep an eye out for strong young men in his hometown, as they are looking for two new fishers for the next trip. Cho promises a referral fee to Sein if he can bring in some skilled hands. Cho also

CONTACT Renata A. Konrad rkonrad@wpi.edu O Operations and Industrial Engineering Foisie Business School, Worcester Polytechnic Institute, Worcester, MA 01609 
Figure 1. Continuum of Exploitation. Adapted from Skrivánková (2010).

promises Sein a role as supervisor of the new recruits, something that brings a little reprieve from some of the more menial tasks that Sein has been accustomed to since joining his new crew.

This paper begins with a descriptive scenario we developed, bringing together fishers' stories shared with us over the past three years in working with a wide variety of stakeholders in the seafood industry in Thailand. We include this scenario to highlight the oftentimes complex and shifting dynamics and roles within labor exploitation, such as how Ohnmar was initially recruited and vulnerable to exploitation, only to eventually turn into an exploiter himself. We will revisit this scenario several times to provide a contextualized example informed by real-world insights linked to the concepts we present in our discussion. This work builds on the understanding that labor exploitation can be mapped onto a spectrum, ranging from what the International Labor Organization (ILO) refers to as "decent work" (ILO, 2013) at one end, through various labor and criminal law violations, to extreme exploitation or "forced labour" (Andrees \& ILO, 2008) at the other (refer to Figure 1).

This continuum of exploitation (Skr̂ivánková, 2010) shows the relationship between labor exploitation and forced labor, highlighting the process of human trafficking as a series of exploitative acts that moves the worker toward a situation of forced labor. More formally, we defer to the UN Protocol to Prevent, Suppress and Punish Trafficking in Persons, Especially Women and Children (2000) (otherwise known as the Palermo Protocol) for a definition of trafficking. The three constituent elements of trafficking are: the action of recruiting, transporting, transferring, harboring or receiving people; by the improper means of threat, force, fraud, deception, coercion, or the abuse of power or a position of vulnerability; for the purpose of exploitation. In the case of minors, this definition only includes elements of action and purpose of exploitation. Labor trafficking is then a subset of these situations, where the purpose of exploitation is work. We also refer to the continuum as it illustrates that a work situation that begins as consensual and mutually beneficial, can evolve into an oppressive and exploitative situation (Weitzer, 2014). In Sein's example, we find evidence of abuse of vulnerability, deception, restriction of movement, physical violence, debt bondage, abusive working and living conditions and excessive overtime.

\section{"Second Generation" of Anti-trafficking Responses}

In 2015, United Nations (UN) member states unanimously adopted the Sustainable Development Goals (SDGs) which, amongst many other targets, include taking immediate and effective measures to "eradicate forced labour, end modern slavery and human trafficking by 2030 [...] and by 2025 end child labour in all its forms" (Target 8.7; United Nations, 2018). However, recent data suggests that at the current rate of progress, achieving SDG 8.7 by 2030 is impossible (Minderoo Foundation, 2019), warranting the exploration of novel approaches in the way we conceptualize, research, and address the problem of trafficking.

The first generation of human trafficking and modern slavery eradication efforts and research were largely "superficial patch-type" responses (Zimmerman \& Kiss, 2017, p. 3). Traditionally perceived as a law enforcement issue, more recently policy-makers and researchers have made concerted efforts to identify social factors which facilitate human trafficking (e.g., Cho, 2015; Hernandez \& Rudolph, 2015) resulting in more survivor services and prevention responses such as awareness campaigns (Alpert \& Chin, 2017; Rothman et al., 2017), training health care providers to recognize signs of trafficking (Chisolm-Straker et al., 2012; Gibbons \& Stoklosa, 2016; Ross et al., 2015), and promoting safer labor 
migration through legal, regulated channels (David et al., 2019; Zimmerman et al., 2015). While such intervention efforts are important in addressing aspects of labor trafficking, these activities often operate independent of one another and the knowledge, understanding, and evidence base of how to best prevent trafficking, support victims, and hold perpetrators accountable remains limited (Davy, 2016).

The $4 \mathrm{P}$ approach (prevention, prosecution, protection and partnership) is the basis of international cooperation promoted to fight trafficking and is enshrined in both the Palermo Protocol and the Council of Europe Convention against Human Trafficking. The complex interplay of social, economic, political, and cultural factors that give rise to labor trafficking demands such a comprehensive approach to developing effective interventions (U.S. State Dept, 2009). To begin the "second generation" of anti-trafficking responses, there is a need for a systematic, integrated approach across the migration pathway (Kiss \& Zimmerman, 2019) and human trafficking supply chain (KammerKerwick et al., 2018) that "addresses structural conditions in addition to individual-level behaviors and risks" (Kiss \& Zimmerman, 2019, p. 2). At the same time, attention should also be paid to the conditions surrounding the "demand chain" for cheap labor that drives exploiters to engage in illicit recruitment, or to carry out employment under working conditions that are below statutory standards (Cyrus \& Vogel, 2015). There is a need to develop intervention frameworks that recognize the genuine complexity surrounding trafficking networks and dynamics and can integrate the effectiveness of multiple response efforts. This paper describes how an epidemiological perspective and approach can be used as a framework to conceptualize and study labor trafficking through a public health lens. This can help to further enhance the $4 \mathrm{P}$ approach, most prominently the prevention component, as part of the "second-generation" of anti-trafficking research and response.

\section{Conceptualizing Trafficking as a "Disease"}

To study trafficking through a public health lens is to, in essence, think about it as a "disease". From a medical philosophical perspective (Margolis, 1976), disease can be defined as:

whatever is judged to disorder or to cause disorder, to the minimal integrity of the body and mind relative to the functions of avoidance of death, prolongation of life, restriction of pain, gratification of desires, and insuring security of person, body, and property. (p. 253)

For those working in, or familiar with, the anti-trafficking space, it likely does not require much of a logical jump to see how trafficking maps neatly onto this specific philosophical definition of disease. Trafficking robs individuals of the freedom to pursue their desires and frequently subjects them to physical and sexual violence as a tool to break their bodies, minds, and spirits and exert further control. Victims' movements are restricted, their identity documents confiscated, and their wages withheld. Trafficking can end as a fatal experience for individuals whether it be on a construction site in Qatar (Human Rights Watch, 2017), a fishing boat in Thailand (Environmental Justice Foundation, 2015), or a cobalt mine in the Democratic Republic of Congo (Amnesty International, 2013).

A quick internet search reveals the immense frequency with which the various forms of human trafficking are described in terms of being an "epidemic" by researchers (Bales, 2009; Butler, 2015; Hendrix, 2010; Territo \& Kirkham, 2010), NGOs and the private sector (OSCE, 2015; The Anti-Slavery Collective, 2018; Thomson Reuters, 2016; Trasatti \& Miller, 2019; Woolf, 2019; ZOE International, 2019), and the popular media (BBC News, 2015; Fortune, 2019; Al Jazeera, 2013; New York Times, 2018; Time, 2019). Even according to the leading multilateral bodies such as the UN and the European Council, the number of victims of human trafficking has reached "epidemic proportions" (UNODC, 2007). An epidemic is a term that is used to describe the incidence of a disease that occurs beyond normal expectancy in a specific community or region (Merrill, 2017). We argue that within such a framing, epidemiology, otherwise known as the science of public health, is particularly relevant to the study of trafficking because it provides an approach to identify risk and casual factors, estimate incidence and prevalence, and effectively allocate resources. 
Human trafficking has also been described as a "pandemic" (De Chesnay, 2013; Ngban et al., 2009), which is an epidemic that spreads across a significant number of regions and countries and impacts a large population. Given the transnationality of the phenomenon and the global estimates of the prevalence of modern slavery (ILO, 2017), the term pandemic is perhaps also an appropriate designation. One other term that appears much less frequently, if at all, to describe trafficking is "endemic". In the public health context, this describes a disease that remains intractable and ongoing in a community despite actions taken to eradicate it (Merrill, 2017). Given the frequency of revictimization and the reality that trafficking remains in existence in spite of significant resources dedicated to its eradication, trafficking can also be characterized as an endemic problem. Toney-Butler and Mittel (2020) explicitly refer to human trafficking as a disease and attempt to define its etiology, epidemiology, and pathophysiology in a more traditional medical approach. Leading experts in the field have previously used the "disease" analogy to help in framing the issue of trafficking (Bales, 2012, p. 32; Kara, 2010, p. 6). Beyond the philosophical and semantic perspective and rhetoric however, there are also practical elements in which the nature of trafficking resembles that of a disease.

Trafficking physically, psychologically, and emotionally sickens those individuals and communities that are afflicted by it. Its propagation is mediated by a network of social contacts (usually family and close relations) and can be likened to the spread of certain infectious diseases. These social networks can be analyzed and tracked so the origins of victimization can be established, and perpetrators identified (Cockbain, 2018), similar to the process of contact tracing for infectious disease. Frontline responders such as labor inspectors, police officers, and civil society actors "diagnose" cases through victim identification, triage these cases, and provide service referrals just as healthcare professionals do for diseases. Trafficking survivors receive various forms of treatment, including medical care, to recover from their experience. There are many risk factors associated with trafficking and being exposed to compounding vulnerabilities magnifies overall risk - similar to comorbidities in traditional health problems. Like many infectious diseases such as HIV/AIDS and tuberculosis, human trafficking disproportionately affects the most marginalized and vulnerable populations. Outbreaks of infectious disease are associated with, and can amplify, documented trafficking risk factors such as diminished economic opportunity, increased criminal activity and competition for resources (Worsnop, 2019). Environmental destruction is linked to the spillover of novel infectious diseases into human populations (Quammen, 2012), and so too human trafficking is inextricably linked to environmental destruction and climate change (Bales, 2016; Brown et al., 2019; Jackson et al., 2020).

Due to the inherent complexities of both trafficking and infectious disease there can be no true equivalent or direct side-by-side comparison between the two concepts in a traditional, biomedical sense. From a theoretical perspective however, this paper will further illustrate that the two concepts are comparable in many ways and justifies the use of insights and methodologies from public health within the anti-labor trafficking domain, particularly through the use of a social epidemiological analysis. Disease prevention is the fundamental basis of public health and if trafficking is conceptualized as a "disease", insights and methodologies adapted from public health may be well suited to advance anti-trafficking efforts. Epidemiology is a core branch of study within the field of public health that analyzes disease causation to explain how diseases originate, spread and can be prevented. Epidemiological thinking is well suited to assess complex trafficking dynamics and how to interrupt them as it considers the interconnected nature of causal and risk factors at the individual, community, and environmental levels. Moreover, labor trafficking research directly relates to two subdisciplines of epidemiology. Occupational epidemiology studies the effects of workplace exposures on the frequency and distribution of disease (Checkoway et al., 1989) and implementing strategies from an occupational health perspective has been suggested as a way to combat labor trafficking (Ronda-Pérez \& Moen, 2017). Social epidemiology examines the effects of social-structural factors on states of health (Honjo, 2004) and social epidemiologists are well-positioned to document and explain the forms of employment associated with labor trafficking and the relationship between precarious work and health (Muntaner, 2016). 
Moving beyond the conceptual analogies laid out above, developments in research and practice support the premise that labor trafficking can be thought of as a "disease". Examples include the addition of disease classification codes for human trafficking (AHA, 2018), the use of screening tools for healthcare practitioners to identify trafficking in clinical settings (Greenbaum, Dodd et al., 2018; Konstantopoulos \& Owens, 2018), the inclusion of trafficking in medical education curriculum (Arulrajah \& Steele, 2018; Stoklosa et al., 2015; Talbott et al., 2020) and the expanding literature base on the intersection between trafficking and public health (Le, 2018). Shifting the anti-trafficking research paradigm toward being public health centric requires multidisciplinary collaboration and stakeholder engagement. For example, the nonprofit HEAL (Health, Education, Advocacy and Linkage) Trafficking brings together professionals and survivors to help advance this paradigm through direct service provision, education and training, academic research and policy advocacy. As this nascent and interdisciplinary field of research grows, trafficking will be increasingly linked to concepts of disease in its own respective context.

In recent years a growing case has materialized to call on public health engagement in addressing modern slavery and to describe an emergent public health approach to the issue (Chisolm-Straker \& Stoklosa, 2017; Greenbaum, 2020; Such et al., 2020). Epidemiology, with its particular promise for interdisciplinary application, can be used to help achieve this objective. As Akers and Lanier (2009, p. 397) note, "the methods and theories used by epidemiologists in tracking and studying disease processes have transcended the realm of traditional biomedical science and are now integral to diverse fields of study within the social and behavioral sciences".

\section{Epidemiologic Problem Oriented Approach (EPOA)}

Conceptualizing labor trafficking through an epidemiological lens is encompassing as it first identifies and characterizes the context and second, examines strategies for management and solutions rooted in that identification and characterization. An epidemiologic problem oriented approach (EPOA) provides a scientific framework for the collection, organization, and analysis of epidemiological information which facilitates the development of systematic and structured knowledge bases. Used in the field of public health as a tool to inform decision making (Lane et al., 2010), the EPOA enables the creation of decision support models which can be used to assess causal processes and outcomes. Developing such a structure is pertinent to the enhanced comprehension of labor trafficking dynamics by predicting the susceptibility of a person to trafficking, understanding the relationship between victims and traffickers, and evaluating the impact of responses.

The EPOA methodology has been used in the study of infectious diseases such as HIV/AIDS (Nganwa et al., 2010; Tameru et al., 2012), African trypanosomiasis (Habtemariam, 1989), highly pathogenic avian influenza (Lane et al., 2010), and bovine tuberculosis (Dibaba \& Daborn, 2019). Using the knowledge base generated through an EPOA, researchers have developed dynamic models for computational epidemiologic case studies (Habtemariam, 1989; Nganwa et al., 2010), identified infection risk in epidemics (Lane et al., 2010), conducted quantitative risk assessments (Tameru et al., 2012), and better described disease transmission dynamics (Dibaba \& Daborn, 2019). To apply the EPOA in the context of labor trafficking we build upon our conceptual framing laid out earlier and draw further comparisons between elements of labor trafficking and disease.

In its design, the EPOA is comprised of two interdependent elements - the Problem Identification/ Characterization triad (otherwise known as the classic epidemiologic triad) and the Problem Management/Solution triad (Habtemariam, 1989). These two triads are interlinked by the diagnostic procedure linkage and the individual components of each triad are also intertwined (Nganwa et al., 2010; Tameru et al., 2012). Figure 2 shows an example of the structure of the EPOA framework as it applies to HIV/AIDS.

The epidemiologic triad (as shown in section A of Figure 2(a)) is a conceptual framework in public health used to model the transmission dynamics of an infectious disease. The triad consists of three main components: a host - an organism that is vulnerable to a disease and influenced by 


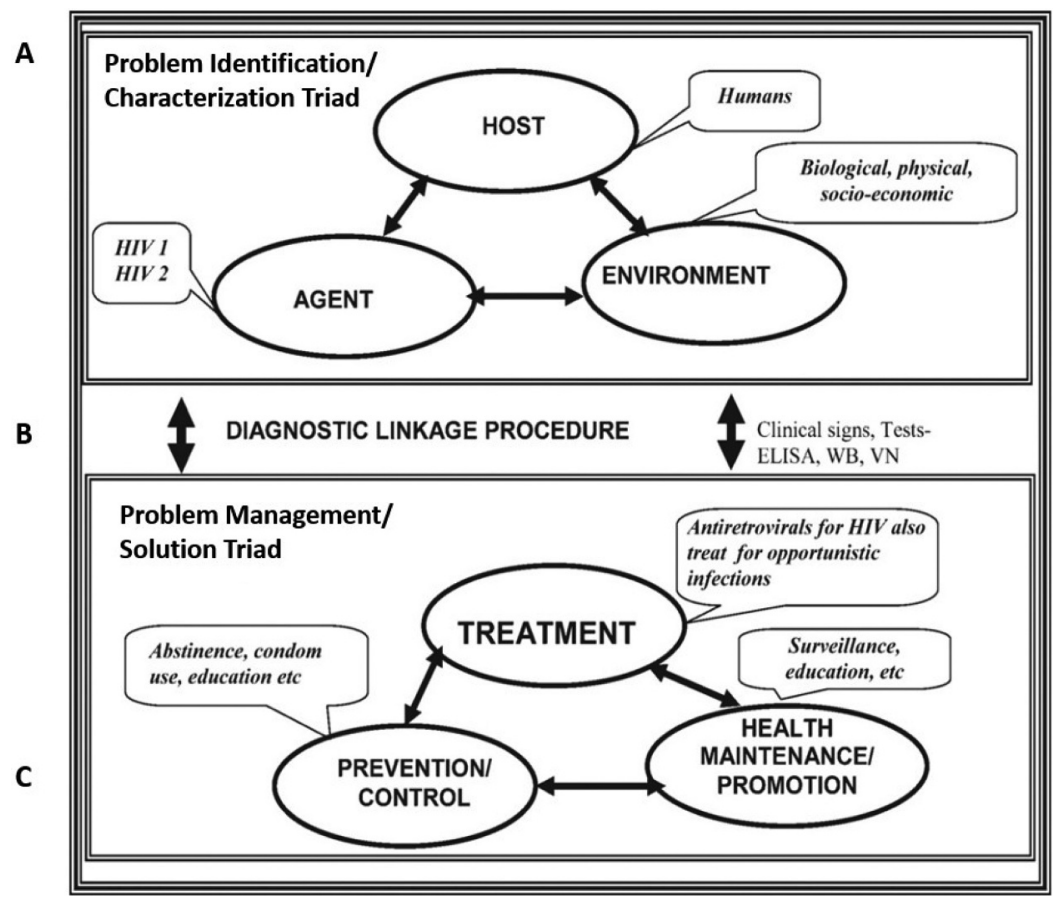

Figure 2. Example of the Epidemiologic Problem Oriented Approach model applied to HIV/AIDS (adapted from Nganwa et al., 2010): (A) problem identification/characterization triad; (B) diagnostic linkage procedure; (C) problem management/ solution triad.

exposure, susceptibility, and response to causative agents (Gregg, 2002); an environment - a set of extrinsic factors that influence the host's susceptibility and exposure to disease and functions to bring the host and agent together (Nelson, 2005) and an external agent - a factor that becomes internalized and whose presence or relative amount is necessary for a disease to occur (Gerstman, 2003). Within this model, a disease results from the interconnected interaction between the agent, environment and host. The Centers for Disease Control and Prevention (CDC) states that, "the development of appropriate, practical, and effective public health measures to control or prevent disease requires assessment of all three components and their interactions" (2012, p. 52). In the case of vector borne diseases, a fourth concept is added to the triad, to represent an entity that conveys the agent from one host to another (Merrill, 2017).

Since there are no true equivalents in a traditional, biomedical sense when comparing infectious diseases to a social phenomenon such as trafficking (versus comparing one infectious disease to another such as Zika to Ebola), we adopt a social epidemiologic analysis to strengthen our position of comparison and contextualize labor trafficking for application within the EPOA. Social epidemiology builds on the traditional epidemiologic triad and focuses explicitly on the role of social determinants in disease transmission to identify characteristics that affect patterns of disease distribution and to understand the role of socio-structural factors from an individual and population perspective (Poundstone et al., 2004).

\section{The EPOA Applied to Labor Trafficking}

\section{Problem Identification/Characterization Triad (Epidemiological Triad)}

Building from the definitions above, we link parallel, analogous concepts from the characterization of infectious diseases to that of labor trafficking and provide a simplified explanation for each of the respective components of the epidemiological triad (Table 1). Table 1 also refers to the scenario 
Table 1. The Epidemiological Triad of Labor Trafficking.

\begin{tabular}{|c|c|c|c|}
\hline Component & Traditional Public Health Definition & $\begin{array}{c}\text { Analogous Definition for Labor } \\
\text { Trafficking }\end{array}$ & Scenario \\
\hline Host & An organism susceptible to disease. & An individual at risk of labor trafficking & $\begin{array}{l}\text { Ohnmar (before } \\
\text { promotion), Sein, Cho, } \\
\text { villagers in Sein's } \\
\text { hometown }\end{array}$ \\
\hline Environment & $\begin{array}{l}\text { External factors that influence the host's } \\
\text { susceptibility and exposure to disease. }\end{array}$ & $\begin{array}{l}\text { Push and pull factors that impact } \\
\text { voluntary and involuntary } \\
\text { migration and labor patterns }\end{array}$ & $\begin{array}{l}\text { Lack of employment } \\
\text { opportunities in } \\
\text { Myanmar } \\
\text { (Comparatively) larger } \\
\text { income in Thailand }\end{array}$ \\
\hline Agent & $\begin{array}{l}\text { A virus, bacterium, or parasite. Something } \\
\text { that exists external to the host, that when } \\
\text { internalized, causes the disease state. }\end{array}$ & $\begin{array}{l}\text { Structural violence that is embodied in } \\
\text { conjunction with host susceptibility } \\
\text { and environmental factors. }\end{array}$ & $\begin{array}{l}\text { Necessity to travel to } \\
\text { Thailand to seek work } \\
\text { Compliance with } \\
\text { restrictions imposed by } \\
\text { Ohnmar at port }\end{array}$ \\
\hline Vector & $\begin{array}{l}\text { Transmits the disease by conveying the agent } \\
\text { from one host to another. }\end{array}$ & $\begin{array}{l}\text { Intermediaries involved in the } \\
\text { trafficking process that bring } \\
\text { together the agent, host, and } \\
\text { environment. }\end{array}$ & Ohnmar (after promotion) \\
\hline
\end{tabular}

presented in the introduction of the paper for a contextualized example, highlighting the four components (host, environment, agent and vector) as they are applied to labor trafficking.

Defining the at-risk population is a critical factor in understanding the epidemiology of any disease (Bonita et al., 2006). We define a susceptiblehost as an individual at risk of being subject to labor trafficking. Risk factors and vulnerabilities for the host to be exposed to the disease (i.e. being trafficked) at the individual and relationship level include, but are not limited to, migration/refugee status, gender, sexual orientation, history of maltreatment, high risk behavior, low education/literacy levels, and socioeconomic status (David et al., 2019; Greenbaum, Titchen et al., 2018; ILO, 2014). These underlying risk factors create disparities between a vulnerable person and a potential exploiter and are also associated with employment precariousness and adverse working conditions, both of which are further linked to trafficking (Muntaner et al., 2010). Just as certain individuals are at a higher risk of contracting an infectious disease because they are immunocompromised, complex and multifaceted levels of vulnerability underlie those individuals at greatest risk of being trafficked. Trafficking research has largely focused on risk factors such as demographic variables; however these are nonmodifiable in nature and primarily help in identifying potential target groups for intervention. Although non-modifiable, such factors are still important for consideration within broader contextual analysis as they can moderate or amplify risk among socio-demographically defined populations.

While the experience of victimization focuses on harm to the host, the violence of human trafficking impacts relationships and occurs within a context beyond just the individual level. As such, analysis of risk factors must also consider community, organizational and structural factors as well. To illustrate how these multi-level factors influence one another and interact, experts have proposed the utility of the Socioecological Model from public health. Increasingly being advocated as a method for creating prevention strategies against trafficking (Chisolm-Straker \& Stoklosa, 2017; Greenbaum, Titchen et al., 2018; Kilanowski, 2017; U.S. Department of Health and Human Services, 2019), this model illustrates how interventions must be targeted across multiple levels in order to achieve and sustain maximum preventative impact. Social norms and influences exist across every level from macro-ecological to micro-interpersonal and contribute in different ways to the positioning of the individual embedded within these varying levels.

Oftentimes the individual level risk factors are further aggravated by the environment component of the epidemiological triad which includes macro-level events and structures (global, national, and community) that impact the likelihood of disease exposure. Political instability, climate change, natural disasters, epidemic outbreaks, inadequate human and economic development, 
authoritarianism and political repression, demographic increases and geopolitical/economic shifts can all be described as "push" factors (Bales, 2007; ILO, 2016b; Worsnop, 2019). These exert pressure on individuals and families contributing to increased patterns of migration, including higher risk taking in the migration process, and therefore greater potential exposure to vulnerabilities that may result in trafficking (ILO, 2016b). On the flip side, "pull" factors that incentivize people to voluntarily migrate exist, also putting individuals at potential risk as they may be willing to accept greater uncertainties or substandard processes arising from their perceived value of migration. The increasing demand for cheap and readily available goods and services in wealthier regions of the world, higher wages, the promise of a better future abroad, potential for educational advancement, potential to send remittances to their home country, and family reunification are all examples of "pull" factors (Raigrodski, 2015). Globalization and trade liberalization have broadly driven an increase in labor migration, and consequently an increase in potential for labor trafficking, highlighting the importance of considering the supply and demand chains when attempting to understand trafficking dynamics. Similar to infectious diseases, greater exposure to environmental risk factors for trafficking can exacerbate susceptibility in already vulnerable populations or be a significant driving force in exposing previously unexposed populations to risk.

The agent, typically a virus, bacterium, or parasite in the case of infectious disease, is something that exists external to the host, that when internalized, leads to the disease state. We argue the agent in labor trafficking is structural violence - a concept informing social epidemiologic work (Rhodes et al., 2012). Farmer et al. (2006, p. 1686) describe structural violence as "social arrangements that are embedded in the political and economic organization of our social world and put individuals and populations in harm's ways". Messages of disempowerment such as racism, inequality, and classism are examples of structural violence that tend to be embodied, either consciously or subconsciously, by the most marginalized and disadvantaged groups of society. Structural violence leads to disenfranchisement and limitations on a potential host's ability to respond to changes in their environment.

Individuals face variable constraints on their agency in situations of labor exploitation and trafficking, such as the confiscation of identity documents, lack of contracts, geographically isolated work environments, the fear of reprisal, threat of denunciation to authorities, physical or digital surveillance, and threats against their families (ILO, 2009a; US State Dept, 2018, 2019). These constraints on agency mean workers in many circumstances have no option other than to comply and accept their exploitation when they face a threat, hence embodying, or internalizing structural violence. Because it considers social influences and disadvantages in describing disease causation, embodiment is a key concept in the field of social epidemiology (Krieger \& Davey Smith, 2004). Although someone may have the desire to leave their exploitative circumstances or actively resist their traffickers, the structural violence imposed upon them in multiple forms constrains them from doing so and embodying the circumstances against their conscious desire. Drawing from our earlier scenario, when Ohnmar wouldn't allow fishers to leave the boat even though they were at port, the fishers complied because of fear of reprisal, lack of alternative employment options, and the power imbalance between the captain and the laborers. For an infectious disease, when the agent becomes internalized, it leads to a negative pathophysiology and causes harm to an individual's health. Likewise, when aspects of structural violence or its aggregate effects are embodied by vulnerable "hosts" in an environment of susceptibility, this leads to the most significant harms.

Structural violence is closely linked to injustice and is often economically driven, as in the case of labor trafficking, through the increasing power of corporations and governance structures that favor businesses or employers over workers' rights (Kiss \& Zimmerman, 2019). These forms of structural violence are in part the result of ideas and practices in the global economy embraced by governments and corporations, such as trends of deregulation, risk transfer and cost reduction measures, and the rise of a consumer society characterized by cheaply produced and readily available products (Abel \& Kunz, 2018). Weak to non-existent labor governance structures and legal frameworks can be further exacerbated by the corruption of public officials from policymakers to law enforcement. Even if grievance and remediation mechanisms are in place in theory, anti-migrant sentiments, language 
barriers, lack of financing, and suspicion of formal institutional actors can render these ineffective in practice. Collectively, these trends represent a social syndemic, analogous to an infectious disease syndemic, where the convergence of two or more diseases act synergistically to magnify the overall burden of disease (Kwan \& Ernst, 2011). Just as HIV amplifies the severity of tuberculosis outbreaks (Porco et al., 2001), messages of disempowerment and constraints of agency are amplified and embodied at a much higher rate due to broader structural violence against laborers.

In many cases, a vector may also be a key part of the infectious disease process and therefore is included in the epidemiologic triad. While certain infectious diseases are characterized by their vector, such as mosquito-borne illnesses, labor trafficking also has vectors that serve as intermediaries (i.e. the traffickers and exploiters themselves, such as Ohnmar in our earlier scenario) bringing together the agent, host, and environment. Traffickers transport, harbor, and exploit victims, often using deception and coercion to exploit the vulnerabilities of victims (Polaris Project, 2015b). Traffickers can include recruiters, labor brokers, document providers, transporters, corrupt officials, pimps, service providers and employers of trafficked persons (ILO, 2009b). Recruitment occurs formally and informally through both public and private labor brokers, acquaintances, family members, and criminal organizations (Andrees et al., 2015). While some labor recruiters may assist with job placement into decent work, others might facilitate exploitation. Recruiters play a significant role in understanding transmission dynamics as these intermediaries often use deceptive, extortive, and coercive practices that result in bringing the host, agent, and environment together, thereby greatly increasing the likelihood of an individual being trafficked. Just as vector control methods for infectious diseases aim to interrupt disease transmission, interventions focused specifically on traffickers present an important potential way to disrupt the human trafficking supply chain.

A vulnerable host living in an environment with exposure to structural violence that increases the likelihood of being trafficked does not necessarily guarantee this person will become a victim. Referring back to our scenario, it is unlikely that Sein would find himself a victim of labor exploitation on a fishing boat in Thailand, without having interactions that brought together the host, agent, vector and environmental factors. The trafficking process requires a connection between all the components of the triad, across the human trafficking supply and demand chains, underpinning the significance of the interconnectedness in understanding transmission dynamics. The inherent complexities associated with labor trafficking means that these components are not entirely comprehensive; however, the EPOA enables the practical organization of the key dimensions of labor trafficking to allow for further study of casual relationships. Seen from a visual perspective (Figure 3), interrupting one or more links between the components would disrupt the overall connected network that is necessary to cause the disease state. Next, we describe the diagnostic procedure linkage and the problem management/solution triad.

\section{Case Definition for Labor Trafficking - Diagnostic Procedure Linkage}

Once a defined threshold of a situation constituting a trafficking case is crossed, the susceptible individual, in epidemiological terms, goes from the healthy state to the disease state. A case definition is a standard set of criteria for classifying the existence of a particular disease, syndrome, or other health condition (CDC, 2012). A case is defined through confirmatory laboratory tests, if available, or combinations of symptoms (subjective complaints), signs (objective physical evidence), and other findings (Page et al., 1995). Epidemiologists use case definitions in ongoing public health surveillance to track the occurrence and distribution of disease in a specific area. The use of a standard case definition ensures that a diagnosis is consistent over time, locale, and clinical practice (Scutchfield \& Keck, 2003). This diagnostic linkage procedure is illustrated in Figure 2(b).

A case definition for labor trafficking can be found in the UN Palermo Protocol. Once a state ratifies and implements this legal instrument, country-specific legal frameworks provide comprehensive guidance on the set of criteria for classifying a case as labor exploitation and labor trafficking (depending on the criminal and/or labor laws that have been violated). It should be noted that the 
full process of "diagnosing" a case of labor exploitation/labor trafficking often involves a lengthy court case. To provide support for frontline responders, a number of researchers have developed triage tools to support proactive and consistent screening of workers for indicators of vulnerability to labor trafficking (International Organization for Migration [IOM], 2019; Thinyane \& Bhat, 2019; UNODC, 2010b). For example, Thinyane and Bhat (2019) developed their system based on the ILO Hard to See Harder to Count methodology (ILO et al., 2012), which includes the ILO's Indicators of Forced Labor and was adapted to the Thai legal framework. The ILO-based definition of labor trafficking is used as a standard in this screening tool which supports labor inspectors, private auditors, and NGOs to assess the vulnerability of a worker in fishing, seafood processing, and manufacturing sectors. The tool aims to support frontline responders in the initial screening phase of victim identification rather than perform a complete diagnosis. Referring back to the continuum of exploitation (Figure 1), labor trafficking is a series of events that move a worker toward a situation constituting forced labor. Identification with certainty can only occur through a lengthy court procedure, however in practice, what is of most interest to frontline responders is to adequately screen for indicators that likely constitute trafficking. This type of screening protocol enabled by triage tools and training for frontline responders can serve as an adequate proxy for the legal "case definition" of labor trafficking as laid out in the Palermo Protocol.

\section{Problem Management/Solution Triad}

The problem management/solution triad (Figure $2(\mathrm{C})$ ) is connected to the epidemiological triad through the diagnostic procedure linkage. This second triad of the EPOA consists of three components: prevention/control, treatment/therapeutics, and health maintenance/promotion. In the analogy to labor trafficking, we slightly reorient these clinical categorizations to better fit the context. We redefine the three components as health promotion, monitoring and surveillance, and treatment (Table 2). Health promotion enables people to exercise increased agency and control over their own health and covers a wide range of social and environmental interventions that address the root causes of disease (WHO, 2016). Monitoring is generally described as the observation of an intervention in a specific program, while surveillance involves the ongoing collection of data to inform action (Lee et al., 2010). Treatment is a form of intervention that is intended to reduce or eliminate the disease burden in someone who has already developed a health condition. These three all fall under the umbrella term of what constitutes "prevention" in a public health framework, operating at different levels known as primary, secondary and tertiary respectively.

Primary prevention aims to limit the incidence of disease by controlling risk factors in target populations (Gullotta \& Bloom, 2014) and is most closely akin to what we will further describe as the health promotion component. Secondary prevention can be defined as the early diagnosis and management of a disease to prevent further complications (Tulchinsky \& Varavikova, 2014) which we link to the monitoring and surveillance component. Finally, tertiary prevention aims to reduce the

Table 2. The Labor Trafficking Problem Management Triad.

\begin{tabular}{|c|c|c|c|}
\hline Component & Traditional Public Health Definition & $\begin{array}{l}\text { Prevention } \\
\text { Level }\end{array}$ & Context Specific Examples for Labor Trafficking \\
\hline $\begin{array}{l}\text { Health } \\
\text { Promotion }\end{array}$ & $\begin{array}{l}\text { Interventions that address the root causes } \\
\text { of disease }\end{array}$ & \multirow[t]{3}{*}{ Primary } & $\begin{array}{l}\text { Awareness-raising campaigns, socio-economic } \\
\text { development, fair recruitment practices, etc. }\end{array}$ \\
\hline Monitoring & Surveillance & & \multirow{2}{*}{$\begin{array}{l}\text { Observation of program interventions and the } \\
\text { ongoing collection of data to inform action }\end{array}$} \\
\hline $\begin{array}{l}\text { and } \\
\text { Secondary }\end{array}$ & $\begin{array}{l}\text { Social compliance audits/labor inspections } \\
\text { for multinational corporations, checks at } \\
\text { border crossings and screenings by } \\
\text { healthcare professionals }\end{array}$ & & \\
\hline Treatment & $\begin{array}{l}\text { Forms of intervention that are intended to } \\
\text { reduce or eliminate disease burden }\end{array}$ & Tertiary & $\begin{array}{l}\text { Multidisciplinary rehabilitative care (medical, } \\
\text { psychological, legal services, shelter); } \\
\text { comprehensive reintegration services for survivors }\end{array}$ \\
\hline
\end{tabular}


impact of a disease after it has already occurred (Kirch, 2008) which we link to the treatment component. It is important to note that even though these components are separated in definition for the purpose of our descriptions, they are not independent of one another nor are they mutually exclusive. Rather, most activities traditionally considered as "labor trafficking prevention" operate across two, if not all three of the triad's components simultaneously due to the significant conceptual and practical overlap. Taken together, these three components outline the sum of interventions that aim to stop labor trafficking from occurring in the first place; identify and track instances of labor trafficking; and ensure the ongoing well-being of labor trafficking survivors.

Four key areas identified by the ILO as being central to labor trafficking prevention efforts are, awareness-raising, ensuring fair recruitment, public and business due diligence, and addressing root causes and risk factors (ILO, 2018). Most trafficking health promotion strategies are designed to address one or more of the following: reducing the vulnerability of potential victims through social and economic development; enforcement of criminal and civil laws against exploitation and trafficking; discouraging the demand for the services of trafficked persons; outreach and public education; border control; and preventing corruption of public officials (The Advocates for Human Rights, 2016; UNODC \& Global Programme Against Trafficking in Human Beings, 2008). In source countries of labor migrants, health promotion (i.e. primary prevention) activities may include microcredit schemes, awareness raising campaigns, and community protection networks; while in destination countries, activities may include migrant hotlines, campaigns targeting consumers, and workplace inspections.

One of the most common forms of primary prevention is awareness-raising campaigns to educate the broader population about labor trafficking and risk factors. A wide range of communication tools can be used to achieve this such as public service announcements, radio, television, social media, printed information and victim testimonials (ILO, 2018). Evaluations of mass media campaigns provide evidence that they are an effective way to improve awareness and understanding of trafficking within target groups (National Agency Against Trafficking in Persons, 2014; Thainiyom, 2011). Similarly, mass media campaigns involving awareness raising and information dissemination have also shown evidence of effectiveness in public health initiatives such as smoking cessation programs (Bala et al., 2017). Beyond educating the general public, migrants and prospective migrants face unique risks of falling victim to labor trafficking and require targeted awareness-raising programming. Pre-departure orientation programmes, another example of a primary prevention activity, are important tools to reduce the vulnerability of migrant workers and enable them to maximize their overseas employment experience (Asis \& Agunias, 2012). Most instances of labor trafficking begin as a voluntary labor migration decision, therefore promoting safe migration through legal channels should be a key focus of primary prevention. Programmes should draw on evidence regarding local migration perspectives, expectations, patterns, decision-making processes, and the migrants' understanding of employment conditions in international or domestic destinations (Buller et al., 2015). When labor migrants are provided with accurate information regarding the migration process through a pre-departure orientation, they are able to make more informed decisions, weighing the pros and cons, and understanding the potential risks. Mobile phone applications such as "MigApp" developed by IOM (2017) and "Subhayatra" (Happy Journey) developed by Nonresident Nepalis Association, Asia Foundation and Young Innovation (in collaboration with ILO, 2016a) are other examples of tools that work to prevent instances of labor trafficking by providing migrant workers with access to verified government information, grievance mechanisms, and safe migration assistance.

The ILO promotes fair recruitment practices as fundamental to labor trafficking prevention strategies, particularly at the primary level. Platforms, such as Recruitment Advisor developed by the International Trade Union Confederation (ITUC, 2018), promote fair recruitment and by extension function as a health promotion activity by providing prospective migrant workers reviews of agencies and information about workers' rights. Initiatives such as the International Recruitment Integrity System (IOM, 2015) developed by the IOM and a coalition of government, private and civil society actors, encourage due diligence for the private and public sectors through the establishment of 
standard setting, compliance, and monitoring mechanisms as a way of preventing labor trafficking by unscrupulous recruiters and employers. Activities targeted toward both recruitment agencies and migrant workers themselves, helps to reduce risk and aid in prevention on both the supply and demand chains that facilitate labor trafficking. While rigorous evaluations of labor trafficking prevention activities are scarce, in a recent evaluation of a commercial sexual exploitation prevention program, participants demonstrated changes in attitudes and behaviors, coupled with a reduction in abuse victimization and enhanced knowledge about services and resources (Rothman et al., 2019). Disease control combines systems of monitoring and surveillance, the third component of the triad, with intervention strategies that, over a prolonged period of time are employed to reduce the frequency of a specific disease (Christensen, 2001). A public health approach to anti-trafficking efforts incorporates surveillance both locally and globally (Greenbaum, 2020). Most closely related to secondary prevention's priority of early disease diagnosis, monitoring and surveillance mechanisms exist to identify cases of labor trafficking through activities such as social compliance audits and labor inspections for multinational corporations (UNODC, 2018), checks at border crossings (Zhang et al., 2014), and screenings conducted by healthcare professionals (Sousou Coppola \& Cantwell, 2016). Monitoring ongoing changes in patterns of trafficking is crucial to understanding and disrupting transmission dynamics, given that traffickers modify their methods of operation in response to legislative changes, enforcement levels, and market demand (IOM, 2004).

Trafficking surveillance systems allow for the collection of three major types of data: (1) information about victims and their vulnerability factors; (2) criminal networks, and (3) the effectiveness of laws and policies - all of which are necessary to form robust trafficking data regimes (UN InterAgency Project on Human Trafficking [UNIAP], 2010). Effective monitoring and surveillance generates the information necessary to inform both treatment and health promotion activities. Once descriptive epidemiology (i.e. data collection) and analytic epidemiology (i.e. mapping trends and patterns) are substantiated through comprehensive data regimes, transformative approaches can be implemented to interrupt risk and promote protective factors. Improvements in monitoring and surveillance can also shift the dynamic from a reactive approach to a proactive one where consistent screening can lead to increased levels of early victim identification.

Due to the hidden nature of human trafficking and labor exploitation and the uneven geographic distribution of occurrence, traditional epidemiological surveillance methods such as random sampling among national populations, or receiving data from as many sources as possible, may not be practical, feasible, or cost-effective (Walk Free Foundation, 2016). Human trafficking sentinel surveillance is an alternative proposed to address these challenges (Feingold, 2010; Thinyane \& Sassetti, 2019) which has been implemented in a few instances (UNIAP, 2010, UNIAP, 2011). A sentinel surveillance system is comprised of a network of carefully selected sentinel sites, or nodes, where there is a higher than average probability of detecting the condition of interest (Bai et al., 2017). This surveillance system is meant to select population samples that are representative of particular groups and are more effective at signaling trends and early detection of health related events and diseases (Braeye et al., 2019; Porta, 2014). Sentinel surveillance systems can offer insights into source and destination hotspots for trafficking, locality-specific vulnerabilities, and overcome the challenges of estimating the prevalence of a disease in an inherently hard to reach population (UNIAP, 2010). Sentinel surveillance has been advocated as "a means to move towards policy that is informed by and responsive to the fluid nature of trafficking and migration" (Feingold, 2010, p. 36) and it has been suggested that technology could support the proactive and consistent screening, collation, and analysis of these patterns (Thinyane \& Sassetti, 2019).

For those who survive a trafficking experience, most will need some form of multidisciplinary rehabilitative care because of their exposure to violence, deprivation and severe occupational hazards (Kiss et al., 2015). Interventions and responses that would fall under the treatment component can include a wide range of medical, psychological, legal, translation, and rehabilitative services, as well as temporary shelter for individuals immediately post victimization (UNODC \& Global Programme Against Trafficking in Human Beings, 2008). This component is akin to tertiary prevention, which 
aims to reduce the impact of a disease after it has already occurred. Medical and psychological treatments are targeted toward the physical and mental health problems resulting from labor trafficking experiences - deep cuts, burns, headaches, broken bones, post-traumatic stress disorder, depression, anxiety, as well as treatment for those who experienced sexual violence (Kiss et al., 2015). Other types of comprehensive services and trauma-informed care include case management, transportation assistance, life skills and job readiness programs and individual or group therapy (Polaris Project, 2015a). More broadly defined, these activities comprise the process of reintegration for survivors as they rebuild relationships within a community, oftentimes in their country of origin, at the physical, socio-economic, socio-political, and cultural levels (Talens \& Landman, 2003).

Since survivors of trafficking are frequently re-trafficked within two years of having exited a trafficking situation (Jobe, 2010), there is a need for ongoing treatment to stop the "disease" from reoccurring. Long-term supportive services are especially necessary as survivors may return to their communities to face stigma, social exclusion, a lack of alternative economic opportunities and suffer from ongoing complications of injuries or health problems that occurred during their trafficking experience (Oram et al., 2012). Although extremely rare in practice, survivors of trafficking are entitled to forms of financial compensation under international law (Article 6(6) of the UN Trafficking Protocol and Article 25(2) of the UN Convention Against Transnational Organized Crime (UNODC, 2000), and when actualized, this form of "treatment" can be both a psychological and financial support on the road to recovery and reduce the likelihood of re-victimization (Cusveller, 2015). Reiterating the overlap and connection between each of the levels of prevention, interventions designed to reduce re-victimization must operate across multiple levels simultaneously. While primary prevention can reduce re-victimization through systematic changes to hiring practices, revictimization is not linear and even with supportive treatments after being trafficked (tertiary prevention) an individual may decide to migrate once again under exploitative circumstances out of economic necessity. As such, breaking the cycle of re-victimization is of particular importance when considering labor trafficking interventions.

Vectors, (i.e. those individuals who are involved in the recruitment and trafficking processes), represent a critical point for potential targeted interventions. Social networks including family, friends, and acquaintances constitute a key element of the migration and recruitment pathways for migrant workers (Buller et al., 2015; UNODC, 2010a). However, despite the component of trust on the part of the prospective migrant being recruited, recruiters in one's proximal social network may not fully understand the risks of migration themselves; or may actively deceive someone to their own benefit, fully understanding the implications. Cure Violence is an example of a successful public health approach toward a complex social phenomenon - community violence reduction - that bears some similarities to aspects of labor trafficking. This program aims to create individual-level and community level change by targeting individuals at the highest risk of spreading violence to others and intervening to change their behaviors and attitudes (Butts et al., 2015). It relies on three key principles; interrupting the transmission of violence directly, changing the thinking of potential transmitters, and changing group norms regarding violence (Butts et al., 2015). Throughout its various program operations in North America, the Cure Violence approach has led to substantial reduction in shootings, perpetration of violent crime, and cultural attitudes supporting violence (Tomberg \& Butts, 2016). Changing cultural norms is important in addressing widespread beliefs and social practices that marginalize individuals and condone situations that increase the risk of trafficking (Greenbaum, 2020). By targeting interventions specifically toward the vector, such as in Cure Violence, it is possible to interrupt the ongoing transmission of the "disease" and such an approach may also have utility if adapted to the anti-trafficking context.

Applying the EPOA to labor trafficking results in a well-defined conceptual diagram that highlights the interconnectedness between components of characterization, diagnosis and management (Figure 3). Defining each triad and decomposing each respective component organizes information and variables into a practical representation of an inherently complex system. This framework offers a novel way of 


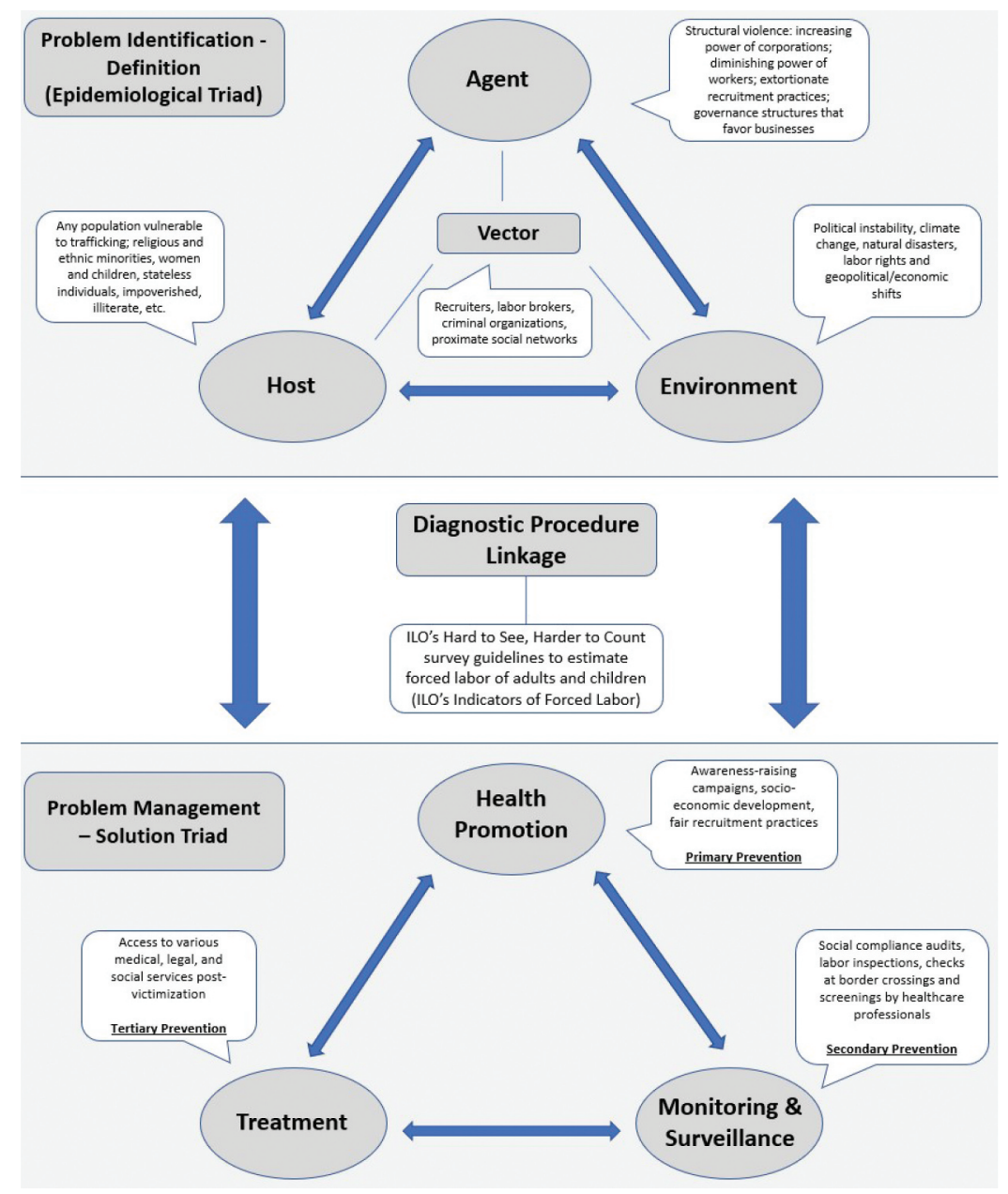

Figure 3. The Labor Trafficking Epidemiologic Problem Oriented Approach (EPOA).

conceptualizing trafficking dynamics and promotes an epidemiological understanding of labor trafficking.

\section{Relevance of Epidemiology to Anti-trafficking Research}

We have presented a specific methodological approach to characterizing the various aspects of labor trafficking causation and response using epidemiological thinking. More broadly however, we use this as a case to anchor the relevance of epidemiology within the ongoing study of labor trafficking. Epidemiologic processes such as surveillance, risk factor exploration, risk group identification, and program implementation/evaluation can all help policymakers and advocates better combat trafficking (Todres, 2011). Below we outline several activities fundamental to epidemiology that are well suited to help overcome the challenges faced by the various stakeholders interested in eradicating human trafficking. 


\section{Identification of Risk and Causal Factors}

Epidemiology is a unique science as it studies the distribution of diseases and underlying causes through consideration of political, economic, social, and scientific factors. The extent to which a person is vulnerable to trafficking can very rarely be simplified to or determined by just one isolated factor. Rather, it is a complex combination of multi-level, interconnected variables that are not yet comprehensively elucidated. Epidemiological research employs various types of studies to be able to quantitatively assess and estimate the magnitude of association between potential risk factors and disease outcomes (Jewell, 2003). Additionally, population health studies, which are conducted using epidemiological methods, help to characterize and understand social issues through a public health lens (Slutkin et al., 2018). For example, labor market inequalities, which are key drivers in the persistence of labor trafficking, have been explored in some population health studies to understand the influence of employment relations and their health impact at the macro-level (Muntaner et al., 2010). Such studies are increasingly being advocated as a method to describe the causes of labor trafficking, to analyze the health impacts of victimization, and to develop appropriate responses to address the root causes of trafficking.

\section{Estimation of Incidence and Prevalence}

Improving the precision of incidence and prevalence estimates has been identified as a priority for the next generation of public health research on human trafficking (Rothman et al., 2017). Epidemiological approaches have been proposed, and in many cases implemented, as a way to generate incidence studies (e.g., number of new people trafficked over a given time period; Fedina \& DeForge, 2017) and prevalence studies (e.g., number of people ever trafficked, or over a specified period). Methodologies frequently used in epidemiological studies to measure hidden or hard-toreach populations, such as Respondent Driven Sampling (Curtis et al., 2008) and Capture-Recapture Analysis (Van Dijk \& van der Heijden, 2015) - have been used to estimate the number of victims of forced labor and trafficking. The use of epidemiologic methodologies can help to reduce sampling bias and overcome some of the challenges of using secondary data to make national and global estimates (Fedina \& DeForge, 2017).

\section{Surveillance Systems}

Surveillance is the foundation of descriptive epidemiology in which the goal is to define the frequency and distribution of health-related events (Long et al., 2017). Modified epidemic curves - a graphical representation of the number cases of infectious disease organized by date or time of onset (Nelson, 2005) - can be useful in mapping human trafficking patterns (Todres, 2011). Human trafficking data collection, typically fragmented and disjointed, could potentially become more reliable and useful when combined with sentinel surveillance systems. For example, the 2009 UNIAP Sentinel Surveillance project utilized this epidemiological methodology in the Mekong sub-region to generate statistically reliable data regarding the prevalence, severity, trends and changes of Cambodian trafficking victims in Thailand (UNIAP, 2010). A robust system of data collected through epidemiologic surveillance would contribute to the ability to track changes in patterns of trafficking over time and to assess the effectiveness of anti-trafficking interventions. The recent adoption of ICD-10 codes in the United States for recording cases of trafficking and forced labor represents a comprehensive classification system that lends itself to epidemiological surveillance and population health data analysis (Macias-Konstantopoulos, 2018).

\section{Allocation of Resources \& Provision of Information}

The burden of labor trafficking, as with many epidemics, far outstrips the resources that are available to treat susceptible and diseased individuals (Dangerfield et al., 2019), and accordingly resources must be directed to maximize impact. An epidemiological lens directs us to consider the interaction of multiple factors that bring about trafficking, put sub-populations at risk of exploitation and trafficking, and to appraise potential response mechanisms to minimize these risks, or diminish trafficking 
incidence. From this vantage point, it is possible to evaluate decisions related to resource allocation. Resource allocation, sometimes referred to as priority setting, is defined as the distribution of resources among programmes, populations or regions that are competing for the same funds (Martin \& Singer, 2003). Despite significant financial investment and the seriousness of the crime of human trafficking, many anti-human trafficking interventions continue to operate without an adequate evidence base (Davy, 2016; Foot et al., 2015), or a systematic evaluation of how to allocate resources. Action is required to increase quality evaluations of anti-human trafficking programs; to ensure that programs are targeted, implemented, and delivered effectively; and to improve the knowledge concerning the impact of programs (Davy, 2016). Indeed, having modeled the spread of disease using dynamic epidemic models researchers have been able to successfully determine the potential impact of various disease intervention strategies, prioritize prevention needs and develop resource allocation plans for treatment and eradication (Aleman et al., 2011; Büyüktahtakın et al., 2018; Eaton et al., 2015; Gopalappa et al., 2012, 2017; Zaric \& Brandeau, 2001). Utilizing such frameworks and methodologies from epidemiology and adapting them to the context of labor trafficking have the potential to improve the efficacy and impact of anti-trafficking measures.

\section{Concluding Thoughts}

A significant risk exists that the UN Sustainable Development Goal Target 8.7, aimed at eradicating labor trafficking, will not be met by the intended target date of 2030. Novel approaches are needed regarding how the anti-trafficking community conceptualizes and addresses the broad issue of labor trafficking. Epidemiological methodologies have successfully studied and intervened in other global public health issues such as obesity, smoking, and violence as well as chronic infectious diseases such as HIV/AIDS. There is an increasing recognition of the role that tools in the field of public health, particularly epidemiology, can play in addressing labor trafficking. Through contextualized comparisons with infectious disease epidemiology - the "disease" of labor trafficking, described through an interplay of hosts, agents, and environments, bears enough similarities to justify modeling this phenomenon by using and adapting existing epidemiological frameworks. This approach forms the basis of systematic analysis and provides a characterization of the trafficking phenomena through a lens of social epidemiology. Human trafficking and labor trafficking are routinely referred to in popular media outlets, academic research, and policy spheres as being "epidemics" of global proportions. If trafficking is indeed a disease of epidemic proportions, then the science of studying and preventing epidemics is well suited to help put an end this grave human rights violation.

\section{ORCID}

Hannah Thinyane (ID) http://orcid.org/0000-0003-0491-4048

\section{References}

Abel, C. F., \& Kunz, K. (2018). Unsettling the memes of neoliberal capitalism through administrative pragmatism. In Margaret Stout (Ed.), From austerity to abundance? (pp. 35-58, Vol. 6). Emerald Publishing Limited. https://doi.org/ $10.1108 /$ S2045-794420180000006002

The Advocates for Human Rights. (2016). Labor trafficking protocol guidelines. Minnesota Dept of Health and United States of America, 2019. Labor Trafficking Protocol Guidelines: Identifying and Responding to Victims of Labor Trafficking 24 Years Old and Under. Available at https://www.theadvocatesforhumanrights.org/uploads/labor_ trafficking_protocol_guidelines_final.pdf

AHA. (2018). Factsheet: ICD-10-CM coding for human trafficking. American Hospital Association.

Akers, T. A., \& Lanier, M. M. (2009). "Epidemiological criminology": Coming full circle. American Journal of Public Health, 99(3), 397-402. https://doi.org/10.2105/AJPH.2008.139808

Al Jazeera. (2013). Slavery: A 21st century “epidemic”. Jane Dutton (presenter). Available at https://www.aljazeera.com/ programmes/insidestory/2013/10/slavery-21st-century-epidemic-201310188844258481.html 
Aleman, D. M., Wibisono, T. G., \& Schwartz, B. (2011). A nonhomogeneous agent-based simulation approach to modeling the spread of disease in a pandemic outbreak. INFORMS Journal on Applied Analytics, 41(3), $301-315$. https://doi.org/10.1287/inte.1100.0550

Alpert, E. J., \& Chin, S. E. (2017). Human trafficking: Perspectives on prevention. In Chisolm-Straker, Makini, and Hanni Stoklosa (Eds.), Human trafficking is a public health issue (pp. 379-400). Springer.

Amnesty International. (2013) . Profits and loss: Mining and human rights in Katanga. Democratic Republic of the Congo.

Andrees, B., ILO. (2008). Forced labour and human trafficking: Handbook for labour inspectors. International Labour Office.

Andrees, B., Nasri, A., \& Swiniarski, P. (2015). Regulating labour recruitment to prevent human trafficking and to foster fair migration: Models, challenges and opportunities [Data set]. Koninklijke Brill NV. https://doi.org/10.1163/22107975_HRD-4022-2015040

The Anti-Slavery Collective. (2018, July 19). Our Mission. https://theantislaverycollective.org/our-mission/

Arulrajah, P., \& Steele, S. (2018). UK medical education on human trafficking: Assessing uptake of the opportunity to shape awareness, safeguarding and referral in the curriculum. BMC Medical Education, 18(1), 137. https://doi.org/10. 1186/s12909-018-1226-y

Asis, M. M. B., \& Agunias, D. R. (2012). Strengthening pre-departure orientation programmes in Indonesia, Nepal and the Philippines. International Organization for Migration, Issue Brief No. 5 Sept 2012, Available at file://C:/Users/ rkonrad/Downloads/PredepartureOrientation\%20(1).pdf

Bai, Y., Yang, B., Lin, L., Herrera, J. L., Du, Z., \& Holme, P. (2017). Optimizing sentinel surveillance in temporal network epidemiology. Scientific Reports, 7(1), 4804. https://doi.org/10.1038/s41598-017-03868-6

Bala, M. M., Strzeszynski, L., \& Cahill K. (2017). Mass media interventions for smoking cessation in adults. Cochrane Database of Systematic Reviews. 2008;(1):CD004704. https://doi.org/10.1002/14651858.CD004704.pub4

Bales, K. (2007). What predicts human Trafficking? International Journal of Comparative and Applied Criminal Justice, 31(2), 269-279. https://doi.org/10.1080/01924036.2007.9678771

Bales, K. (2009). Winning the fight: Eradicating slavery in the modern age. Harvard International Review.

Bales, K. (2012). Disposable people: New slavery in the global economy. University of California Press.

Bales, K. (2016). Blood and earth: Modern slavery, ecocide, and the secret to saving the world. Random House Publishing Group.

BBC News. (2015, July 28). Human trafficking: Lives for sale.

Bonita, R., Beaglehole, R., Kjellström, T., \& Organization, W. H. (2006). Basic epidemiology. World Health Organization.

Braeye, T., Quoilin, S., \& Hens, N. (2019). Incidence estimation from sentinel surveillance data; a simulation study and application to data from the Belgian laboratory sentinel surveillance. BMC Public Health, 19(1), 982. https://doi.org/ 10.1186/s12889-019-7279-y

Brown, D., Boyd, D. S., Brickell, K., Ives, C. D., Natarajan, N., \& Parsons, L. (2019). Modern slavery, environmental degradation and climate change: Fisheries, field, forests and factories. Environment and Planning E: Nature and Space, 2514848619887156. 1-17. https://doi.org/10.1177/2514848619887156

Buller, A. M., Stoklosa, H., \& Zimmerman, C. (2015). Labour exploitation, trafficking and migrant health: Multi-country findings on the health risks and consequences of migrant and trafficked workers. International Organization for Migration.

Butler, C. N. (2015). The racial roots of human trafficking (2015). UCLA Law Review, 62(6), 1464, SMU Dedman School of Law Legal Studies Research Paper No. 179, Available at SSRN: https://ssrn.com/abstract=2655840

Butts, J. A., Roman, C. G., Bostwick, L., \& Porter, J. R. (2015). Cure violence: A public health model to reduce gun violence. Annual Review of Public Health, 36(1), 39-53. https://doi.org/10.1146/annurev-publhealth-031914122509

Büyüktahtakın, İ. E., Des-Bordes, E., \& Kıbış, E. Y. (2018). A new epidemics-logistics model: Insights into controlling the Ebola virus disease in West Africa. European Journal of Operational Research, 265(3), 1046-1063. https://doi.org/ 10.1016/j.ejor.2017.08.037

Dicker R. C, Coronado F, Koo D, Gibson P. R. (2012). Principles of epidemiology in public health practice, third edition. an introduction to applied epidemiology and biostatistics. Atlanta, GA: Centers for DiseaseControl and Prevention, 2006.

Checkoway, H., Pearce, N. E., \& Crawford-Brown, D. J. (1989). Research methods in occupational epidemiology. Oxford University Press.

Chisolm-Straker, M., Richardson, L. D., \& Cossio, T. (2012). Combating slavery in the 21st century: The role of emergency medicine. Journal of Health Care for the Poor and Underserved, 23(3), 980-987. https://doi.org/10.1353/ hpu.2012.0091

Chisolm-Straker, M., \& Stoklosa, H. (2017). Human trafficking is a public health issue: A paradigm expansion in the United States. Springer.

Cho, S.-Y. (2015). Modelling for determinants of human trafficking. Social Science Research Network.

Christensen, J. (2001). Epidemiological concepts regarding disease monitoring and surveillance. Acta veterinaria Scandinavica, 42(Suppl 1), S11. https://doi.org/10.1186/1751-0147-42-S1-S11 
Cockbain, E. (2018). Offender and victim networks in human trafficking. Taylor \& Francis.

Curtis, R., Terry, K., Dank, M., Dombrowski, K., \& Khan, B. (2008). Commercial sexual exploitation of children in New York City, volume one: The CSEC population in New York City: Size, characteristics, and needs. U.S. Department of Justice.

Cusveller, J. (2015). Compensation for victims of human trafficking: Inconsistencies, impediments and improvements, Master thesis criminology, Faculty of Law, VU University Amsterdam/La Strada International (August 2015).

Cyrus, N., \& Vogel, D. (2015). Demand arguments in debates on trafficking in human beings: Using an historical and economic approach to achieve conceptual clarification. Demand AT Working Paper No. 1. Vienna: ICMPD.

Dangerfield, C. E., Vyska, M., \& Gilligan, C. A. (2019). Resource allocation for epidemic control across multiple sub-populations. Bulletin of Mathematical Biology, 81(6), 1731-1759. https://doi.org/10.1007/s11538-019-00584-2

David, F., Bryant, K., \& Joudo Larsen, J. (2019). Migrants and their vulnerability to human trafficking. Modern Slavery and Forced Labour.

Davy, D. (2016). Anti-Human Trafficking Interventions. American Journal of Evaluation, 37(4), 486-504. https://doi. org/10.1177/1098214016630615

De Chesnay, M. (2013). Psychiatric-mental health nurses and the sex trafficking pandemic. Issues in Mental Health Nursing, 34(12), 901-907. https://doi.org/10.3109/01612840.2013.857200

Dibaba, A. B., \& Daborn, C. J. (2019). Epidemiology of bovine tuberculosis in Africa. In A. B. Dibaba, N. P. J. Kriek, \& C. O. Thoen (Eds.), Tuberculosis in animals: An African perspective (pp. 89-126). Springer International Publishing. https://doi.org/10.1007/978-3-030-18690-6_7

Eaton, J. W., Bacaër, N., Bershteyn, A., Cambiano, V., Cori, A., Dorrington, R. E., Fraser, C., Gopalappa, C., Hontelez, J. A. C., Johnson, L. F., Klein, D. J., Phillips, A. N., Pretorius, C., Stover, J., Rehle, T. M., \& Hallett, T. B. (2015). Assessment of epidemic projections using recent HIV survey data in South Africa: A validation analysis of ten mathematical models of HIV epidemiology in the antiretroviral therapy era. The Lancet. Global Health, 3(10), e598608. https://doi.org/10.1016/S2214-109X(15)00080-7

Environmental Justice Foundation. (2015) . Thailand's seafood slaves. Human Trafficking, Slavery and Murder in Kantang's Fishing Industry.

Farmer, P., Nizeye, B., Stulac, S., \& Keshavjee, S. (2006). Structural violence and clinical medicine. PLoS Medicine, 3(10), e449. https://doi.org/10.1371/journal.pmed.0030449

Fedina, L., \& DeForge, B. R. (2017). Estimating the trafficked population: Public-health research methodologies may be the answer. Journal of Human Trafficking, 3(1), 21-38. https://doi.org/10.1080/23322705.2017.1280316

Feingold, D. (2010). Trafficking in numbers: The social construction of human trafficking data. In P. Andreas \& K. M. Greenhill (Eds.), Sex, drugs and body counts: The politics of numbers in global crime and conflict (pp. 46-74). Cornell University Press.

Foot, K. A., Toft, A., \& Cesare, N. (2015). Developments in anti-trafficking efforts: 2008-2011. Journal of Human Trafficking, 1(2), 136-155. https://doi.org/10.1080/23322705.2014.980663

J Galucci, 'Human Trafficking Is an Epidemic in the U.S. It's alsobig business', Fortune. (2019). Human trafficking is an epidemic in the U.S. It's also big business. https://fortune.com/2019/04/14/human-sextrafficking-us-slavery

Gerstman, B. B. (2003). Epidemiology kept simple: An introduction to traditional and modern epidemiology. John Wiley \& Sons.

Gibbons, P., \& Stoklosa, H. (2016). Identification and treatment of human trafficking victims in the emergency department: A case report. The Journal of Emergency Medicine, 50(5), 715-719. https://doi.org/10.1016/j.jemermed. 2016.01.004

Gopalappa, C., Farnham, P. G., Hutchinson, A. B., \& Sansom, S. L. (2012). Cost effectiveness of the National HIV/AIDS strategy goal of increasing linkage to care for HIV-infected persons. Journal of Acquired Immune Deficiency Syndromes (1999), 61(1), 99-105. https://doi.org/10.1097/QAI.0b013e31825bd862

Gopalappa, C., Sansom, S. L., Farnham, P. G., \& Chen, Y.-H. (2017). Combinations of interventions to achieve a national HIV incidence reduction goal: Insights from an agent-based model. AIDS (London, England), 31(18), $2533-2539$. https://doi.org/10.1097/QAD.0000000000001653

Greenbaum, J. (2020). A public health approach to global child sex trafficking. Annual Review of Public Health, 41(1), 481-497. https://doi.org/10.1146/annurev-publhealth-040119-094335

Greenbaum, V. J., Dodd, M., \& McCracken, C. (2018). A short screening tool to identify victims of child sex trafficking in the health care setting. Pediatric Emergency Care, 34(1), 33-37. https://doi.org/10.1097/PEC.0000000000000602

Greenbaum, V. J., Titchen, K., Walker-Descartes, I., Feifer, A., Rood, C. J., \& Fong, H. (2018). Multi-level prevention of human trafficking: The role of health care professionals. Preventive Medicine, 114, 164-167. https://doi.org/10.1016/j. ypmed.2018.07.006

Gregg, M. B. (2002). Field epidemiology. Oxford University Press.

Gullotta, T. P., \& Bloom, M. (2014). Encyclopedia of primary prevention and health promotion. Springer US.

Habtemariam, T. (1989). Utility of epidemiologic simulation models in the planning of trypanosomiasis control programs. Annales de la Societe belge de medecine tropicale, 69(Suppl 1), 109-124; discussion 144. AppData/Local/ Microsoft/Windows/INetCache/IE/6NBSYA86/1989asbms109.pdf 
Hendrix, M. C. (2010). Enforcing the U.S. Trafficking victims protection act in emerging markets: The challenge of affecting change in India and China Note. Cornell International Law Journal, 43(1), 173-206. http://apps.webofknow ledge.com/InboundService.do?product=WOS\&Func=Frame\&DestFail=http\%3A\%2F\%2Fwww.webofknowledge. com\%3FDestParams\%3DUT\%253DWOS\%25253A000280446700006\%2526customersID\%253Datyponcel\% 2526smartRedirect\%253Dyes\%2526action\%253Dretrieve\%2526mode\%253DFullRecord\%2526product\%253DCEL\% $26 \mathrm{SrcAuth} \% 3 \mathrm{Dat}$ p oncel\% $26 \mathrm{SrcApp} \% 3 \mathrm{Dliteratum} \% 26 \mathrm{Dest}$ A p p \% 3 D CEL \% 26 e \% 3Dvn8ANvzP517ofjW9HZn2GKsLsxoX2SQHkBUKpo4fO7WhDzEneoECeA\%253D\%253D\&SrcApp= literatum\&SrcAuth=atyponcel $\& S I D=7 F a 66 \mathrm{czv} 45$ aexei5OCT\&customersID =atyponcel $\&$ smartRedirect $=$ yes $\&$ mode $=$ FullRecord\&IsProductCode $=$ Yes\&Init $=$ Yes\&action $=$ retrieve\&UT $=$ WOS\%3A000280446700006

Hernandez, D., \& Rudolph, A. (2015). Modern day slavery: What drives human trafficking in Europe? European Journal of Political Economy, 38, 118-139. https://doi.org/10.1016/j.ejpoleco.2015.02.002

Honjo, K. (2004). Social epidemiology: Definition, history, and research examples. Environmental Health and Preventive Medicine, 9(5), 193-199. https://doi.org/10.1007/BF02898100

Human Rights Watch. (2017). Qatar: Take urgent action to protect construction workers. Human Right Watch, New York, USA. https://www.hrw.org/news/2017/09/27/qatar-take-urgent-action-protectconstruction-workers

ILO. (2009a). Operational indicators of trafficking in human beings. Geneva: ILO. http://www.ilo.org/global/topics/ forced-labour/publications/WCMS_105023/lang-en/index.htm

ILO. (2009b). Training manual to fight trafficking in children for labour, sexual, and other forms of exploitation. Textbook 2 - Advocacy Against Child Trafficking at Policy and Outreach Levels. Geneva: ILO.

ILO. (2013). Decent work indicators: guidelines for producers and users of statistical and legal framework indicators: ILOmanual: second version / International Labour Office. - Geneva: ILO, 2013.

ILO. (2014, May 20). Profits and poverty: The economics of forced labour. International Labour Office. http://www.ilo. org/wcmsp5/groups/public/_ed_norm/_declaration/documents/publication/wcms_243391.pdf

ILO. (2016a) . Safe migration mobile app released. AP Migration. http://apmigration.ilo.org/news/safe-migrationmobile-app-released

ILO. (2016b). The climate change-Human trafficking Nexus.Bangkok: IOM Regional Office for Asia and the Pacific.

ILO. (2017) . Global estimates of modern slavery: Forced labour and forced marriage. Geneva, Switzerland. Retrieved from http://www.ilo.org/global/publications/books/WCMS_575479/lang-en/index.htm

ILO. (2018). Ending forced labour by 2030: A review of policies and programmes. International Labour Organization, Geneva: ILO, 2018 ISBN: 9789221327448 (print).

International Labour Office, International Labour Office, Special Action Programme to Combat Forced Labour, \& ILO International Programme on the Elimination of Child Labour. (2012). Hard to see, harder to count: Survey guidelines to estimate forced labour of adults and children. ILO.

IOM. (2004). Changing patterns and trends of trafficking in persons in the Balkan region. International Organization for Migration.

IOM. (2015). International recruitment integrity system. http://iris.iom.int/what-iris

IOM. (2017, December 15). MigApp. International Organization for Migration.

IOM. (2019, April 30). Mobile App Aids detection of human trafficking at Sea. International Organization for Migration.

ITUC. (2018) . Recruitment advisor. Recruitment Advisor.

Jackson, B., Sparks, J. L. D., Brown, C., \& Boyd, D. S. (2020). Understanding the co-occurrence of tree loss and modern slavery to improve efficacy of conservation actions and policies. Conservation Science and Practice, 2(5), e183. https:// doi.org/10.1111/csp2.183

Jewell, N. P. (2003). Statistics for epidemiology. CRC Press.

Jobe, A. (2010). The causes and consequences of re-trafficking: Evidence from the IOM human trafficking database. Prepared for the International Organization for Migration. http://publications.iom.int/bookstore/free/causes_of_ retrafficking.pdf

Kammer-Kerwick, M., Busch-Armendariz, N., \& Talley, M. (2018). Disrupting illicit supply networks: New applications of operations research and data analytics to end modern slavery. Workshop report and proposed research agenda. University of Texas at Austin. https://doi.org/10.15781/T2J960V32

Kara, S. (2010). Sex trafficking: Inside the business of modern slavery. Columbia University Press.

Kilanowski, J. (2017). Breadth of the socio-ecological model. Journal of Agromedicine, 22(4), 295-297. https://doi.org/10. 1080/1059924X.2017.1358971

Kirch, W. (2008). Encyclopedia of public health: Volume 1: A-H Volume 2: I-Z. Springer Science \& Business Media; 2008 Jun 13.

Kiss, L., Pocock, N. S., Naisanguansri, V., Suos, S., Dickson, B., Thuy, D., Koehler, J., Sirisup, K., Pongrungsee, N., Nguyen, V. A., Borland, R., Dhavan, P., \& Zimmerman, C. (2015). Health of men, women, and children in post-trafficking services in Cambodia, Thailand, and Vietnam: An observational cross-sectional study. The Lancet Global Health, 3(3), e154-e161. https://doi.org/10.1016/S2214-109X(15)70016-1

Kiss, L., \& Zimmerman, C. (2019). Human trafficking and labor exploitation: Toward identifying, implementing, and evaluating effective responses. PLoS Medicine, 16(1), e1002740. https://doi.org/10.1371/journal.pmed.1002740 
Konstantopoulos, W., \& Owens, J. (2018). Adult human trafficking screening tool and guide. Funded by the U.S. Department of Health and Human Services (HHS), Administration for Children and Families, Office on Trafficking in Persons (OTIP).

Krieger, N., \& Davey Smith, G. (2004). "Bodies count," and body counts: Social epidemiology and embodying inequality. Epidemiologic Reviews, 26(1), 92-103. https://doi.org/10.1093/epirev/mxh009

Kwan, C. K., \& Ernst, J. D. (2011). HIV and tuberculosis: A deadly human syndemic. Clinical Microbiology Reviews, 24 (2), 351-376. https://doi.org/10.1128/CMR.00042-10

Lane, C., Tameru, B., Nganwa, D., Habtemariam, T., Asseged, B., Robnett, V., \& Wilson, S. (2010). A quantitative risk assessment for the likelihood of introduction of highly pathogenic avian influenza virus strain H5N1 into U.S. hunter retriever dogs. Avian Diseases, 54(1 Suppl), 699-706. https://doi.org/10.1637/8832-040209-Reg.1

Le, P. D. (2018). Human trafficking health research: Progress and future directions. Behavioral Medicine (Washington, D. C.), 44(3), 259-262. https://doi.org/10.1080/08964289.2018.1480169

Lee, L. M., Thacker, S. B., \& Louis, M. E. S. (2010). Principles and practice of public health surveillance. Oxford University Press.

Long, S. S., Prober, C. G., \& Fischer, M. (2017). Principles and practice of pediatric infectious diseases E-Book. Elsevier Health Sciences.

Macias-Konstantopoulos, W. L. (2018). Diagnosis codes for human trafficking can help assess incidence, risk factors, and comorbid illness and injury. AMA Journal of Ethics, 20(12), 1143-1151. https://doi.org/10.1001/amajethics.2018. 1143.

Margolis, J. (1976). The concept of disease. Journal of Medicine and Philosophy, 1(3), 238-255. https://doi.org/10.1093/ jmp/1.3.238

Martin, D., \& Singer, P. (2003). A strategy to improve priority setting in health care institutions. Health Care Analysis, 11 (1), 59-68. https://doi.org/10.1023/A:1025338013629

Merrill. (2017) . Introduction to epidemiology. Jones \& Bartlett Publishers.

Minderoo Foundation. (2019). Measurement. Action, Freedom.

Muntaner, C. (2016). Global precarious employment and health inequalities: Working conditions, social class, or precariat? Cadernos De Saude Publica, 32(6), 1-5. https://doi.org/10.1590/0102-311X00162215

Muntaner, C., Solar, O., Vanroelen, C., Martínez, J. M., Vergara, M., Santana, V., Castedo, A., Kim, I.-H., \& Benach, J., \& EMCONET Network. (2010). Unemployment, informal work, precarious employment, child labor, slavery, and health inequalities: Pathways and mechanisms. International Journal of Health Services: Planning, Administration, Evaluation, 40(2), 281-295. doi: 10.2190/HS.40.2.h.

National Agency Against Trafficking in Persons. (2014). Prevention campaign impact evaluation. https://rm.coe.int/ $168063 \mathrm{bc} 4 \mathrm{f}$

Nelson, K. E. (2005). Infectious disease epidemiology: Theory and practice. Jones \& Bartlett Learning.

New York Times. (2018). Inside New York's silent sex trafficking epidemic.

Nganwa, D., Habtemariam, T., Tameru, B., Gerbi, G., Bogale, A., Robnett, V., \& Wilson, W. (2010). Applying the epidemiologic problem oriented approach (EPOA) methodology in developing a knowledge base for the modeling of HIV/AIDS. Ethnicity \& Disease, 20(1 Suppl 1), S1-173-177.

Ngban, A. N., Maliki, A. E., \& Asuquo, P. N. (2009). Demographic variables and perception of human trafficking in the South-South Zone of Nigeria. Studies on Home and Community Science, 3(2), 127-130. https://doi.org/10.1080/ 09737189.2009.11885287

Oram, S., Stöckl, H., Busza, J., Howard, L. M., \& Zimmerman, C. (2012). Prevalence and risk of violence and the physical, mental, and sexual health problems associated with human trafficking: Systematic review. PLoS Medicine, 9(5), e1001224-e1001224. https://doi.org/10.1371/journal.pmed.1001224

Organization for Security and Co-operation in Europe's Office for Democratic Institutions and Human Rights (ODIHR). (2015). Ensuring human rights protection in countries of destination: Breaking the cycle of trafficking. http://www.osce.org/odihr/

Page, R. M., Cole, G. E., \& Timmreck, T. C. (1995). Basic epidemiological methods and biostatistics: A practical guidebook. Jones \& Bartlett Learning.

Polaris Project. (2015a). Promising practices: An overview of traumua-informed therapeutic support for survivors of human trafficking. https://polarisproject.org/resources/promising-practices-an-overview-of-trauma-informed-thera peutic-support-for-survivors-of-human-trafficking/

Polaris Project. (2015b, October 12). The Victims \& Traffickers. Polaris.

Porco, T. C., Small, P. M., \& Blower, S. M. (2001). Amplification dynamics: Predicting the effect of HIV on tuberculosis outbreaks. Journal of Acquired Immune Deficiency Syndromes, 28(5), 437-444. https://doi.org/10.1097/00042560200112150-00005

Porta, M. P. (2014). Sentinel surveillance. In M. Porta (Ed.), A dictionary of epidemiology. Oxford University Press. doi: 10.1093/acref/9780195314496.001.0001

Poundstone, K. E., Strathdee, S. A., \& Celentano, D. D. (2004). The social epidemiology of human immunodeficiency virus/acquired immunodeficiency syndrome. Epidemiologic Reviews, 26(1), 22-35. https://doi.org/10.1093/epirev/ mxh005 
Quammen, D. (2012). Spillover: Animal infections and the next human pandemic. W. W. Norton.

Raigrodski, D. (2015). Economic migration gone wrong: Trafficking in persons through the lens of gender, labor, and globalization. Indiana International \& Comparative Law Review, 25(1), 79-114. https://doi.org/10.18060/7909.0006

Rhodes, T., Wagner, K., Strathdee, S. A., Shannon, K., Davidson, P., \& Bourgois, P. (2012). Structural violence and structural vulnerability within the risk environment: Theoretical and methodological perspectives for a social epidemiology of HIV risk among injection drug users and sex workers. In P. O'Campo \& J. R. Dunn (Eds.), Rethinking social epidemiology: Towards a science of change (pp. 205-230). Springer Netherlands. https://doi.org/ 10.1007/978-94-007-2138-8_10

Ronda-Pérez, E., \& Moen, B. E. (2017). Labour trafficking: Challenges and opportunities from an occupational health perspective. PLoS Medicine, 14(11), e1002440. https://doi.org/10.1371/journal.pmed.1002440

Ross, C., Dimitrova, S., Howard, L. M., Dewey, M., Zimmerman, C., \& Oram, S. (2015). Human trafficking and health: A cross-sectional survey of NHS professionals' contact with victims of human trafficking. BMJ Open, 5(8), e008682. https://doi.org/10.1136/bmjopen-2015-008682

Rothman, E. F., Farrell, A., Paruk, J., Bright, K., Bair-Merritt, M., \& Preis, S. R. (2019). Evaluation of a multi-session group designed to prevent commercial sexual exploitation of minors: The "My life my choice" curriculum. Journal of Interpersonal Violence, 088626051986597. https://doi.org/10.1177/0886260519865972

Rothman, E. F., Stoklosa, H., Baldwin, S. B., Chisolm-Straker, M., Kato Price, R., \& Atkinson, H. G. (2017). Public health research priorities to address US human trafficking. American Journal of Public Health, 107(7), 1045-1047. https:// doi.org/10.2105/AJPH.2017.303858

Scutchfield, F. D., \& Keck, C. W. (2003). Principles of public health practice. Cengage Learning.

Skrivánková, K. (2010). Between decent work and forced labour: Examining the continuum of exploitation. York: Joseph Rowntree Foundation.

Slutkin, G., Ransford, C., \& Zvetina, D. (2018). How the health sector can reduce violence by treating it as a contagion. AMA Journal of Ethics, 20(1), 47-55. https://doi.org/10.1001/journalofethics.2018.20.1.nlit1-1801.

Sousou Coppola, J., \& Cantwell, R. (2016). Health professional role in identifying and assessing victims of human labor trafficking. The Journal for Nurse Practitioners, 12(5), e193-e200. https://doi.org/10.1016/j.nurpra.2016.01.004

Stoklosa, H., Grace, A. M., \& Littenberg, N. (2015). Medical education on human trafficking. AMA Journal of Ethics, 17 (10), 914-921. https://doi.org/10.1001/journalofethics.2015.17.10.medu1-1510.

Such, E., Laurent, C., Jaipaul, R., \& Salway, S. (2020). Modern slavery and public health: A rapid evidence assessment and an emergent public health approach. Public Health, 180, 168-179. https://doi.org/10.1016/j.puhe.2019.10.018

Talbott, J. M. V., Dutcher, J. S., Pougnier, C. A., Calvin, S. L., Roe-Sepowitz, D., \& Kling, J. M. (2020). Review of published curriculum on sex trafficking for undergraduate medical trainees. American Journal of Preventive Medicine, 58(4), 604-611. https://doi.org/10.1016/j.amepre.2019.11.013

Talens, C., \& Landman, C. (2003). Good practices on (Re)integration of victims of traffickign in human beings in six European countries. Z.pl.: BLinN - Novib/Humanitas - Change anti trafficking programme - OXFAM-GB.

Tameru, B., Nganwa, D., Bogale, A., Robnett, V., \& Habtemariam, T. (2012). The role of computational epidemiology and risk analysis in the fight against HIV/AIDS. Journal of AIDS \& Clinical Research, 3(6). 1-4. https://doi.org/10. 4172/2155-6113.1000e107

Territo, L., \& Kirkham, G. (2010). International sex trafficking of women \& children: Understanding the global epidemic. Looseleaf Law Publications.

Thainiyom, P. (2011, October 11). A media campaign to increase awareness and prevention of human trafficking in Asia: Background strategies and outcome evaluation of the MTV EXIT campaign. Third Annual Interdisciplinary Conference on Human Trafficking, 2011. University of Nebraska. Available at https://digitalcommons.unl.edu/cgi/ viewcontent.cgi? article $=1016 \&$ context $=$ humtraffconf3

Thinyane, H., \& Bhat, K. (2019, May 4). Supporting the critical-agency of victims of human trafficking in Thailand. ACM CHI Conference on Human Factors in Computing Systems.

Thinyane, H., \& Sassetti, F. (2019). Apprise: Using sentinel surveillance for human trafficking and labor exploitation. United Nations University Institute on Computing and Society.

Thomson Reuters. (2016). How can you eliminate modern slavery in complex supply chains?https://www.thomsonreuters. $\mathrm{com} /$ content/dam/ewp-m/documents/thomsonreuters/en/pdf/reports/modern-slavery-report.pdf

Time. (2019). The best way to end human trafficking? Defend democracy.

Todres, J. (2011). Moving Upstream: The Merits of a Public Health Law Approach to Human Trafficking. North Carolina Law Review, 89(2), 447-506. https://heinonline-org.ezpxy-web-p-u01.wpi.edu/HOL/Page?handle=hein.jour nals/nclr89\&div=17\&g_sent $=1 \&$ casa_token=\&collection $=$ journals

Tomberg, K., \& Butts, J. A. (2016). Street by street: Cross-site evaluation of the OJJDP community-based violence prevention demonstration program. StatPearls Publishing.

Toney-Butler, T. J., \& Mittel, O. (2020). Human trafficking. StatPearls Publishing. http://www.ncbi.nlm.nih.gov/books/ NBK430910/

Trasatti, M. A., \& Miller, Z. A. (2019). HUMAN TRAFFICKING: How businesses can work to combat the modern slavery epidemic. Risk Management; New York, 66(8), 20-25. http://www.rmmagazine.com/september-2020/ 
Tulchinsky, T. H., \& Varavikova, E. A. (2014). Chapter 2-Expanding the concept of public health. In T. H. Tulchinsky \& E. A. Varavikova Eds., The new public health (3rd ed., pp. 43-90). Academic Press. https://doi.org/10.1016/B9780-12-415766-8.00002-1

U.S. Department of Health and Human Services. (2019). Definitions and principles to inform human trafficking prevention. https://www.acf.hhs.gov/otip/resource/prevention

UNIAP. (2011). Human trafficking sentinel surveillance: Viet Nam-China Border 2010. United Nations Inter-Agency Project on Human Trafficking.

UNIAP (Ed.). (2010) . Human trafficking sentinel surveillance: Poipet, Cambodia, 2009-2010. United Nations InterAgency Project on Human Trafficking.

United Nations. (2018). Global indicator framework for the sustainable development goals and targets of the 2030 Agenda for sustainable development (A/RES/71/313). United Nations Statistics Division: New York, NY, USA (2017). https:// unstats.un.org/sdgs/metadata/

UNODC. (2000) . United Nations convention against transnational organized crime and the protocols thereto. United Nations.

UNODC. (2007). Annual report 2007-United Nations and the rule of law. United Nations Office of Drugs and Crime. Available https://www.un.org/ruleoflaw/files/AR06_fullreport.pdf

UNODC. (2010a). Transnational organized crime threat assessment. https://www.unodc.org/unodc/data-and-analysis/ TOC-threat-assessments.html

UNODC. (2010b) . VITA victim translation assistance: A Handbook for law enformcement officers and victim service providers.

UNODC. (2018). What role can labour inspectors play in the fight against human trafficking? United Nations Office of Drugs and Crime. https://www.unodc.org/unodc/en/human-trafficking/glo-act/what-role-can-labour-inspectorsplay-in-the-fight-against-human-trafficking.html https://www.unodc.org/unodc/en/human-trafficking/glo-act/ what-role-can-labour-inspectors-play-in-the-fight-against-human-trafficking.html

UNODC, \& Global Programme Against Trafficking in Human Beings. (2008). Toolkit to combat trafficking in persons. United Nations Office on Drugs and Crime.

Trafficking in Persons Report. (2009) . Report United States Department of State. Available at http://www.state.gov/j/tip/ rls/tiprpt

Trafficking in Persons Report. (2018). Report United States Department of State. Available at: http://www.state.gov/j/tip/ rls/tiprpt

Trafficking in Persons Report . (2019). Report United States Department of State. Available at http://www.state.gov/j/ tip/rls/tiprpt

Van Dijk, J., \& Van der Heijden, P. G. M. (2015). Multiple systems estimation for estimating the number of victims of human trafficking across the world. United Nations Office on Drugs and Crime.

The Global Slavery Index . (2016). Dalkeith Western, Australia: Walk Free Foun- dation. The rehabilitation.

Weitzer, R. (2014). New directions in research on human trafficking. The Annals of the American Academy of Political and Social Science, 653(1), 6-24. https://doi.org/10.1177/0002716214521562

WHO. (2016). World Health Organization. Report https://www.who.int/westernpacific/news/q-a-detail/what-is-healthpromotion

Woolf, B. (2019, December 11). Solving an epidemic: Human trafficking in America.United States. House Rules Committee Subcommittee on Legislative and Budget Process. Available at https://docs.house.gov/meetings/RU/ RU02/20191211/110314/HHRG-116-RU02-Wstate-WoolfB-20191211.pdf

Worsnop, C. Z. (2019). The disease outbreak-human trafficking connection: A missed opportunity. Health Security, 17 (3), 181-192. https://doi.org/10.1089/hs.2018.0134

Zaric, G. S., \& Brandeau, M. L. (2001). Optimal investment in a portfolio of HIV prevention programs. Medical Decision Making: An International Journal of the Society for Medical Decision Making, 21(5), 391-408. https://doi.org/10.1177/ 0272989X0102100506

Zhang, S. X., Spiller, M. W., Finch, B. K., \& Qin, Y. (2014). Estimating labor trafficking among unauthorized migrant workers in San Diego. The Annals of the American Academy of Political and Social Science, 653(1), 65-86. https://doi. org/10.1177/0002716213519237

Zimmerman, C., \& Kiss, L. (2017). Human trafficking and exploitation: A global health concern. PLoS Medicine, 14(11), e1002437. https://doi.org/10.1371/journal.pmed.1002437

Zimmerman, C., McAlpine, A., \& Kiss, L. (2015). Safer labour migration and community-based prevention of exploitation: The state of the evidence for programming. The Freedom Fundand London School of Hygiene and Tropical Medicine.

ZOE International. (2019). What is human trafficking. Available at https://gozoe.org/what-is-human-trafficking/ 